\title{
Problems and Countermeasures in the Ecological Protection of Shenyang City
}

\author{
Bingbing Cui \\ Shenyang University, Shenyang 110044, China \\ Tel: 86-24-2324-3799Ｅ-mail: bingb-ndb@163.com
}

\begin{abstract}
The development and advance of city is the sign of human civilization, and the crystal of the mutual development of economy, politics, culture, and ecological environment for one age. In the ecological protection, Shenyang city has not protected and destroyed original public services from the view of cultural ecology. The cause is that Shenyang city lacks in the consciousness to maintain the ecology, which seriously influences the development of Shenyang city and threatens human healthy, and has been an important factor to restrain the sustainable development of the city (Li, 2008). Aiming at this problem, many countermeasures such as establishing the volunteer organization of ecological preservation and keeping feasible density are proposed in this article.
\end{abstract}

Keywords: Ecological protection, Ecology, Shenyang

With the development of the human society, the environment protection and ecology have been widely applied in various domains of the city. The development of the ecological concept has made the ecological city be one of the hottest topics nowadays. To maintain the city ecological system and build the city ecological figure is not closely related with the adjustment of Shenyang industrial structure, but directly influence the improvement of about seven millions denizens' habitation condition in Shenyang. Therefore, the research and thinking about the ecological construction and preservation should be widely concerned by the whole society (Li, 2001).

\section{Ecological protection}

Ecological protection is the activity which is guided by the ecological science, follows ecological rules, and consciously adopts certain countermeasures and measures to protect the ecological environment. The emphasis of the ecological protection is to apply the theory and method of the ecology to research and solve the mutual influences between human beings and ecological environment, and harmonize the mutual relationship between the humankind and the ecological circle.

\section{City ecology}

The city ecological system is the unified whole formed because of the mutual influence between urban residents and the environment, and the special artificial ecological system established because of human adapting, processing and rebuilding to the natural environment. The city ecological system includes not only biological factors (plants, animal, bacillus, epiphyte, and virus) and non-biological factors (light, heat, water, and atmosphere), but also human factor, and social and economical factor, and these factors form an interior associated whole by the energy flow, chemical circulation of biological earth, and materials supply and waste disposal system.

\section{Problems existing in the city ecological protection}

\subsection{Misunderstandings in the city ecological construction}

For relationship between the city and the nature, people have a false concept, i.e. "using grass and trees to sprinkle the streets", not "high buildings grow in the grass and trees". At the beginning, the earth belongs to grass and trees, not high buildings and large mansions, and of course, we can not let various wild animals travel in the city, but we can cut the inhabit place for them in the city. Now, in Shenyang, it is hard to see a place with old trees reaching the sky and sleek weeds, and the grasses in wall foots and brickwork joints have been attributed as weeds.

\subsection{Paying more attention to the development and ignoring the environment}

Environment and development are two topics faced by the human society nowadays. Since 1960s, the recovery of world economy and the push of the urbanization process not only quicken the development of society and 
economy, but bring a series of problems about urban energy and ecological environment. In the urban construction and development process of Shenyang, the behavior only emphasizing short-term economic benefits but ignoring long-term environment benefit existed and induced environment pollution, resource waste, and ecological damage. How to utilize energy and protect and improve the environment effectively has been the urgent task at present. To build the ecological city with sustainable development, the first thing is to strengthen the infrastructure construction of the city, perfect the function of the city, optimize the society, economy, and ecological environment of the city, and continually improve human survival and habitation conditions. Combining with the legal guarantee provided by the ecological environment protection, the necessity of the sustainable development of the city is introduced by analyzing the actuality of the ecological environment of the city, and then the durative of the city ecological system is discussed and the relative advices about the ecological environment layout of the city are proposed as follows.

\subsection{Landscape development will invade and occupy the ecological resources}

Like cultural relic, ecological resources such as grassland, lake, island, forest, desert, and gorge are nonrenewable resources which are easily damaged, and if relative protection measures are not adopted, these resources may disappear in the earth. We must cherish the invaluable fortunes given by the nature, and orderly develop the tourism resources under the premise of protection. Many places with beautiful ecological environment largely changed after development. In many ecological landscapes, blindly deforesting and opening ways still are most common, and the original trees in many landscapes have been damaged seriously, and the ground begun to be bared. The pure tourism motivation should be "promoting the ecological protection by the tourism, and promoting the tourism by the ecological protection", and the original idea of the ecological tourism should be leading tourists to enter into the nature and enjoy the nature, and achieve the intention of understanding the nature and increase the environment protection knowledge when adjusting the body and heart and exercising the will.

\section{Countermeasures}

\subsection{Establishing the volunteer organization of ecological preservation (Li, 2007)}

First, the college student volunteer organization of ecological preservation should be established, and their activities could make more people to understand the knowledge about the ecological protection, and many methods such as ecological course, news media, and ecological city website could be used to gradually enhance citizens' consciousness of ecological protection, and only if all people know the importance of ecological protection, the intention of ecological protection could be really achieved, and the ecological sustainable development could be realized. at the same time, the city construction staffs and city managers' quality should be strengthened, and the learning of ecological protection knowledge should be increased.

\subsection{Executing the laws and controlling the pollution strictly}

From the historical experiences of controlling the pollution, to control the environment pollution fully, the laws should be utilized to fight with the illegal phenomena about the environment, and the illegal phenomena should be stroke strictly to reduce the pollution to the minimum degree, and any chance should not be left to the persons who pollute the environment. Though this method will offend some group's benefits, and rejected by some benefit groups, but controlling the pollution strictly is people's will, and it will be advocated and supported by the mass. Therefore, if controlling the pollution strictly is supported by the government, law enforcement officials of environment protection will more strictly execute relative laws in the pollution control.

\subsection{Keeping feasible density}

Feasible density includes feasible population density and feasible habitation density. The population density will influence many aspects of the city ecological system, especially the utilization of resources and the discharge of wastes. At present, the population density in many places of Shenyang has exceeded the ecological bearing capacity, and the bearing capacity of water and fresh air, which bring many problems for the city ecological environment, and increase the charges to improve the ecological environment and city construction. Because people need certain habitation space, and if the habitation density is too large, the crowded phenomena will occur, and many environment problems such life pollution will be increased.

\subsection{Distributing the industries reasonably and improving the industrial structure}

To improve the old industrial distribution in the city and reasonably distribute industries in the new region of the city is the important measure to improve the ecological structure of the city, and prevent the environment pollution of the city. Whether improving the old industrial distribution or distributing industries in the new regions of the city should follow following principles. 
(1) The industrial distribution should accord with the ecological requirements, and the industrial region should be established in the places with big ecological suitability.

(2) The industrial distribution should be guided by the whole layout of the city and the comprehensive control layout of the city environment, and comprehensively consider the economic benefit, social benefit, and environment benefit.

(3) Developing the economy when improving the city ecological structure and promoting the good circulation of city ecology.

In the new city or the new regions of the city, before the industries are distributed, the sequence of the industrial land utilization should be evaluated. In the ecological system of the city, the regeneration process of the economy is the important medium part, and the economic structure has the important influence on the ecological structure of the city and the material circulation and energy exchange of the ecological system. Because the industrial structure is the principal part of the economic structure of the city, so improving the urban industrial structure is very advantageous to improve the ecological structure and promote the good circulation. Because of the difference of the industrial departments and scales, the outputs and sorts of various pollutions per unit production value are also different, so under the premise that the economic target is certain, to change the industrial structure and reduce the discharge of pollution objectively is a positive method to control the environment pollution of the city.

\subsection{Implementing the ecological technology and enhancing the ecological efficiency (Shen, 2004)}

At present, the low ecological efficiency is an important problem for Shenyang. The basic cause of low resource and energy utilization rate and serious environment pollution is that the ecological principle has not been followed. The ecological technical principle includes the dexterity principle, the circulation principle, and the coexistence principle. These three principles should be utilized well for really implementing the ecological technology, and they are also the effective measures and important guarantee to enhance the ecological efficiency. As a high-efficiency natural composite ecological system of society and economy, the city is not a simple chain, and not a single loop, but a closely connected network with interior energy flow, material metabolizing, and information transfer. And the nodes and lines in the network charge for their own functions, and utilize the material energies on different layers, and regenerate the wastes, and various departments and industries coexist together, and the functions and structures of the system could harmonize fully to reduce the energy loss of the system, and enhance the material utilization rate.

\subsection{Strengthening the layout and construction of city parks (Hu, 2001)}

To strengthen the city park layout and construction is the important measure to protect the ecology of the city. The ecological protection could not only control the environment pollution, but strengthen the greenbelt construction, because the green plants and groups are the important part of the city ecological system, and only the city achieves certain green degree, the urban economy could be developed. By the physiological and biological process such as photosynthesis and rising of plants, the microclimate could be improved, and the standard of local climate could be achieved first, and it will also increase the air humidity, make oxygen, absorb harmful gases and dusts, prevent winds and sands, reduce noises, prevent water loss and land erosion, and maintain the ecological balance of the city.

To really protect the ecology of the city and realize the durative of the ecological environment layout of the city, the concept should be renovated first, and the basic principles about ecology and sustainable development should be fully utilized, and the bearing capacity of natural resources and the ecological suitability should be referred to deliver the problems existing in the ecological environment of the city, analyze and harmonize the conflicts between the social and economic development and the ecological environment, prevent the ecological pollutions and achieve the harmonious development of human and nature.

\section{References}

Hu, Taoxiang, Chen, Jiashu \& Chen, Qize. (2001). The Protection of Ecological Environment and the Construction of Municipal Parks. Journal of Guangzhou Landscape Architecture, No.4.

Li, Baoyu \& Liu, Tao. (2008). My Opinions about How to Strength the Urban Ecological Protection in China. Science \& Technology Information, No.35.

Li, Wei, Li, Shengzhi \& Li, Hangxing. (2007). On Five Main Trends of International Ecology Protection. Ecological Economy, No.10.

Li, Yanqing. (2001). The Problems and Countermeasures of the City Ecology Protection in Kaifeng City. Journal 
of Kaifeng University, No.3.

Shen, Manhong \& Lu, Jing. (2004). Study on the Ecological Protection Compensation Mechanism. Zhejiang Academic Journal, No.4. 